\title{
ORIENTATIONS TOWARD INTERPERSONAL ARGUING IN CHILE $^{1}$
}

\author{
Cristián Santibáñez and Dale Hample
}

\begin{abstract}
This paper reports the first empirical results aiming to characterize argumentative practices in Chile. We described features of Chilean interpersonal arguing among university students, compared those results with others obtained in the United States, and also compared the associations among variables from country to country. Chilean men displayed more aggressive and self-oriented arguing profiles than Chilean women. Compared to U.S. Americans, Chileans were more motivated to argue and saw the practice of arguing as more cooperative and civil. Many results and correlational patterns were recognizable from one nation to the other, but some differences deserve notice. For example, several measures that are routinely seen as opposites in the U.S. (e.g., impulses to approach or avoid arguing) have only modest negative correlations in the Chilean data.
\end{abstract}

Keywords: Argument frames; Chile; Cooperativeness; Individualism; Interpersonal arguing.

\section{Introduction}

Home to sixteen million people, about sixty universities, and a developed economy, Chile has not yet been the setting for much social scientific research on interpersonal argument. The purpose of this paper is to provide an initial description of some basic orientations (e.g., approaching or avoiding arguments) to interpersonal arguing in that nation.

Argumentative activity has been studied empirically in Chile, but in a particular focused way. This work has been primarily concerned with the concept of argumentative competence, especially in the practices of primary, secondary, and college students

\footnotetext{
${ }^{1}$ This paper is part of the research project entitled Value, Function and Argumentative Complexity in University Students: The Case in Coquimbo and Santiago's Chilean Regions, supported by the National Chilean Science Commission, project No. 1130584. We would like to thank the University Diego Portale's students who did the field work surveying other students in different universities in Santiago.
} 
(Cademartori and Parra 2004; Cordero 2004; Crespo 2005; González 2009; Larraín and Freire 2012; Marincovich 2007a, 2007b; Marinkovich and Morán 1995; Parodi 2001; Poblete 2003; Salazar 2008; Vicuña and Marinkovich 2008). For example, Jélvez (2008) identified the most frequent argumentative schemes in written texts produced by twelve to thirteen year old students; Jélvez concluded that the argumentative schemes most frequently found in the argumentative texts written by the students (15 to 16 years old) are those called by Perelman as "based on the structure of reality", and that the arguments that were performed were grounded in concrete situations of immediate experience for the students or in their knowledge of a particular situation. Work of a similar nature was carried out by Marinkovich (2007a), whose objective was to establish the competence profile of Chilean scholars in the production of written discourse in two textual typologies. Among the main findings, Marincovich concluded that the most frequent cognitive-rhetorical strategy used by the students participating in the interaction is causation. This is an indicator that students were aware of the existence of a sequential relationship of the arguments in a series. González (2009) analyzed argumentative interaction in the classroom, aiming to describe the argumentative structure of this discursive practice and to characterize some aspects of both students' and professors' linguistic behavior during collective discussions. He showed that the overuse of the teacher's neutral position in the classroom discussions discouraged the students' exposition of viewpoints. Cordero (2004) analyzed the problems facing a group of students when they attempted to make an argumentative thesis. Cordero found that the students developed their theses in an ambiguous or unsuccessful manner because their opinions did not always agree with the demands imposed by the rhetorical context of the school.

Other Chilean research has analyzed the public practice of argumentation regarding important social and cultural issues (Santibáñez 2006, 2010; Wittig 2005). Wittig (2005) described the argumentation regarding the distribution of an emergency anti-conception drug in the Chilean public health network. The points of view of the Church, the government, and Chilean scientists were established. One of Wittig's main conclusions was to underscore the Church's abusive use of the slippery slope argumentative scheme both to defend its view and to frighten the public.

All this work is valuable. For the most part, however, the sort of quantitative survey and experimental research common in the United States has not been conducted in Chile. The bulk of research on argument-relevant predispositions and expectations has been done in the United States, immediately raising questions about the relevance of those empirical results and theoretical conceptualizations to the rest of the world. The present investigation takes its place alongside others that concentrate on one or more nations other than the United States (e.g., Avtgis, Rancer, Kanjeva and Chory 2008; Cionea, Hample and Paglieri 2011; Croucher 2013; Croucher, Oomen, et al. 2010; Croucher, Otten, et al. 2013; Hample and Anagondahalli 2015; Xie, Hample and Wang in press). As this community research project unfolds, we should be able to map some basic argumentation-relevant orientations throughout the world. Some fundamental questions are common to all this cross-cultural work: What U.S.-developed measures and constructs are relevant to other cultures? For those matters that are common, how do members of different cultures compare? Do the common measures have the same associations with one another from country to country? 
What elements of other nations' views of arguing should be fed back into the originating theories developed in the U.S. and which should be used to develop nation-specific accounts of arguing?

\section{Orientations toward interpersonal arguing}

Many ways have been devised to assess people's expectations and understandings of faceto-face arguing, people's general orientations to the activity. Here we have chosen several measures that are reasonably well established, cover fundamental matters, and offer the possibility of cross-national comparisons. By "orientations" we mean to point generally to a variety of measures that capture people's motivations regarding argung, their understandings of what the practice is for and how it feels, what their goals might be when they argue, and some related matters. This study should therefore provide a solid basis for further research on Chilean argument practices.

The first set of measures deals with basic motivational orientations to the practice of interpersonal arguing (Rancer and Avtgis 2014). These are argumentativeness (Infante and Rancer 1982) and verbal aggressiveness (Infante and Wigley 1986). Both instruments are composed of two subscales, one measuring approach impulses and the other measuring avoidance. The essential difference between the concepts concerns what respondents are orienting toward. Argumentativeness is the predisposition to attack the other person's standpoint, evidence, or reasons. The approach/avoid subscales assess whether the respondent is inclined to engage in that sort of communication or to avoid it. It is possible for a person to feel both approach and avoidance impulses at high levels (that is, to be strongly pulled in both directions) or at low levels (that is, to be generally indifferent to the exchange). Verbal aggressiveness is different. This is the predisposition to attack the other interactant's character, identity, personal history, or other features of the person. Here the approach/avoidance subscales measure the inclination to be antisocial (hostile, nasty) or prosocial (polite, careful in what one says). Again, it is possible for a person to be high on both subscales, or low on both. Often, the avoidance score is subtracted from the approach score to give a summary measure of argumentativeness or verbal aggressiveness, but here we will report subscale results separately because this is more informative.

A second group of measures describes people's argument frames (Hample 2003, 2005). This set of instruments was developed to answer the question, "What do ordinary people think they are doing when they argue?" The frames therefore summarize expectations and orientations regarding interpersonal arguing. Three general categories of frames have been developed. The first of these is self-centered and reflects personal reasons for arguing. These goals are utility (to obtain some benefit), identity display (to show off some feature of self), dominance assertion (to show that the respondent is superior to the argument partner in some respect), and play (to argue for entertainment). These goals foreground self and treat the other arguer as a means to own goals. The second category is other-oriented. Here the other person is taken into account in a more authentic, humanistic way. The instruments here are blurting (blurters say whatever they think but non-blurters 
adapt their utterances to the other person's needs), cooperation (its opposite is competition, which does take the other into account but does so manipulatively), and civility (the politeness and constructiveness of the encounter). The final category of frames is reflective and includes only one measure, called professional contrast. This instrument consists of a number of binary oppositions on which argument scholars endorse one possibility but ordinary actors often prefer the other. For instance, scholars think that arguing is an alternative to violence but many people think that arguing leads to violence. A high score on this instrument means that the respondent agrees with scholars. These frame groups move from self-focus to other-focus to abstract reflection, and therefore they are regarded as being in order of sophistication. Because the blurting and utility scales were still under development at the time the present study was designed, they were not included here.

To compensate for the lack of a blurting scale and to provide other informative detail, we also asked respondents to complete an editing task (Hample \& Dallinger 1987; Hample 2005). People were given a persuasive objective and a large number of possible messages they might use to accomplish their aim. For each of these messages, they could endorse it (that is, say that they would be willing to use it) or reject it. For each rejection, they were asked to check the reason for suppression. The reasons are these: The message would be ineffective; the message is too negative to use; the message might hurt self or own projected identity; the message might hurt other or the other's projected identity; the message might damage the arguers' relationship; the message would be irrelevant; the message would be false; or a residual category. The larger the number of endorsed messages, the more the respondent is inclined to blurt (Hample, Richards and Skubisz 2013). The reasons for suppression constitute several categories (Hample and Dallinger 1992): Those that concern effectiveness, those that are person-centered (self, other, and relationship), and those that are discourse-centered (truth and relevance). Editorial choices therefore convey information about the respondent's goals while arguing and the degree to which the person blurts.

Another approach to assessing people's reasons for arguing was the application of Dillard's (1990; Dillard, Segrin and Harden 1989) set of influence goals. These goals are influence (the goal to persuade), identity (protecting self image), interaction (behaving appropriately), relational resource (protecting the relationship), personal resource (protecting personal possessions), and arousal (managing anxiety). That final matter, apprehension about arguing, was also assessed by the Personal Report of Communication Apprehension (McCroskey 1978). These instruments offer another way of understanding why a person might argue or not.

Finally, we added several measures that are not directly concerned with interpersonal arguing. Our reason for this decision was that these are very general measures that have been connected to many social phenomena, and therefore might provide useful clues for the further development of a theory of Chilean argument practice. These measures are the Big Three and self-construals. The Big Three are personality supertraits that are intended to condense a great many specific traits into a few measures (Eysenck and Eysenck 1975; Eysenck, Eysenck and Barrett 1985). The Big Three instrument actually produces four scores: Psychoticism (hostility, coldness), neuroticism (anxiety), extraversion (sociability), and a lie score (formed by noticing unlikely but self-flattering responses). The 
self-construal measures (Singelis 1994) assess whether a person has individualistic (selffocused) or interdependent (group-focused) values and strivings. Our interests in these personality and self-construal measures lie mainly in their associations with the more argumentation-specific instruments summarized above.

These measurements should afford us a useful initial description of Chilean argument orientations. We will get information bearing on whether Chileans are eager or reluctant to argue, the reasons they argue, the delicacy or bluntness with which they argue, and their goals for participating in an exchange at all. In addition, we will obtain basic information on typical personality and cultural orientations, and these may help to explain why the other scores are what they are. In many cases, we will be able to compare Chilean results with those from the U.S. Throughout those comparisons, we will be attending most closely to two issues: Do Chileans have similar or different scores on these instruments? Do the measures have the same relationships to one another in Chile as in other countries? Answers to these questions will clarify the degree to which a distinctly Chilean theory of argumentation is needed, and what its outline might be.

\section{Relevant background to Chilean argumentation practices}

Insofar as we have been able to determine, very little social scientific research of the sort we do here has focused on argumentative practices in Chile. Although that makes the present project more valuable, it is inconvenient for establishing any precise expectations about what will be found. Therefore we provide here some simple background regarding Chile, with the aim of contextualizing Chilean argumentative practice and suggesting very generally how Chileans might approach arguments on public or personal topics (Johnson 2002). We begin by summarizing some matters pertaining mainly to the public sphere (Goodnight, 1982).

Chile's present population is about sixteen million, with about $40 \%$ living in or around the largest city, Santiago. About $70 \%$ of citizens are Catholic. Chile has one of the strongest economies in South America and is technically classed as a "developed" country. The economy is capitalist and organized to feature market forces (O'Ryan, de Miguel and Lagos 2007). Wealth distribution within the population is quite uneven. All citizens participate in a national pension system and receive government-sponsored health care. Chile is multicultural (about half the population is straightforwardly European in origin), with many ethnicities and origin blends dating back to colonial and pre-colonial times but also embracing more recent immigration. Worries about class are more salient than those about race (Baño, Ruiz and Ruiz-Tagle 2008; Torche and Wormald 2004; Vitale 2001).

Chile's political history is filled with violent conflict and instability (Moulian 2009). Magellan landed in present-day Chile in 1520, and Spain aggressively colonized Chile in

the middle of the $16^{\text {th }}$ century. Authoritarian governments have been common, interspersed with varying forms of republicanism or socialism. For the last generation, Chile has had a republican democracy. Chilean independence was achieved in 1818. Chile has had a number of formal constitutions: In 1818, 1822, 1823, 1826, 1828, 1833, 1925, and 1980. 
The 1980 constitution remains in effect, but it has been substantially amended more than a dozen times. Civil wars took place in 1830, 1891, and 1931, and military coups occurred in 1924 and 1973. Many of these conflicts can be superficially summarized as having been about whether centralized autocratic power should be balanced by some sort of conciliar or parliamentary body. Counting the initial military experience in 1818, Chileans have experienced a civil war or coup almost once a generation. Presumably this affects their national understanding of government and its reliability.

Very importantly for modern day Chile, the repressive Pinochet regime that took power in 1973 was overcome at the polls in 1988. Pinochet left the presidency in 1990 but remained commander in chief until 1998, when he was arrested. Since 1988, national authority in Chile has changed peacefully via election several times. The Pinochet dictatorship is regarded by outside observers as having been guilty of widespread human rights violations, including murder, torture, and politically motivated imprisonment. The replacement of Pinochet ushered in many reforms, including much more freedom to speak, write, and argue in public about political matters. Many older Chileans had their sense of public participation formed in the dangerous Pinochet years, but younger Chileans have mainly experienced democracy and freedom of speech.

For our initial set of expectations about public argument in Chile, therefore, we should be alert to matters of class, authoritarianism, and generational differences in willingness to argue. Chileans might well be very sensitive to issues dealing with social and income inequalities, power, and freedoms. This encourages us to move now to summarize some relevant material concerning arguments about personal topics (Johnson 2002).

Chilean family practices, particularly those involving the role of women, have changed substantially in the last 30 years (PNUD, 2010). Women have begun to ask their children to modify their emotional and social behaviour in order to adopt a more open disposition on taking on new roles. Today Chilean women strongly challenge the model of male economic dominance (Herrera and Teitelboim 2011). This is the result of an improvement in women's salaries. Gender equality in Chile reaches 95\% of IHD-IGD (PNUD, 2010). At the same time, women no longer consider themselves incomplete if they are not married. Relationships are based on love instead of patrimonial control, as in the past. The number of marriages has decreased and the number of divorces has increased.

Another salient fact in contemporary Chilean society is the role of secondary and college students in the transformations of the educational system. In the last few years, a chain of student protests has resulted in important modifications regarding educational fees and state support of education. The Chilean educational system has changed from a neoliberal system to one that is more social-democrat. Young people today in Chile are not afraid of challenging what the adult generation built in the Pinochet period and the twenty years post Pinochet.

So as regards personal issue arguments, Chile is moving toward an openness to women's voice and equality. Families are becoming more egalitarian. Education is becoming regarded as something that ought to be available to all. 


\section{Research objectives}

Based on our review of the U.S.-developed descriptions of interpersonal arguing and our general survey of Chilean history and culture, we have several pointed interests in this investigation. Since we judge that direct empirical precedents are unavailable in the literature, we express these interests as research questions.

Our first concern is the possibility of sex differences in how people understand and orient to arguing. Noticing another person's sex is a nearly instant early step in categorizing and perceiving the other, and sex is therefore a fundamental social category. We have noticed that sex roles may be undergoing some change in Chile, as they have in the U.S. in recent generations. We collect our relevant measures under the general label "orientations." They include motivations to argue and to be verbally aggressive, argument frames, editorial inclinations, arguing goals, supertraits, and self-construals.

Research Question 1: Do Chilean men and women display different orientations to interpersonal arguing?

A more general question is whether Chile and the U.S. have similar overall understandings and expectations about arguing. The answer to this question will give an initial indication of the degree to which U.S. findings can safely be exported to Chile. Therefore,

Research Question 2: Do Chileans display similar scores on orientation measures as in the U.S.?

Finally, we take note of the fact that in the U.S., nearly all of these instruments are associated with one another. They (partly) define a dynamic field full of impulses, worries, understandings, and goals that incline a person to some general relationship with the activity of arguing. If the two countries generate noticeably different patterns of association among the variables, that will indicate that U.S. theories need pointed revision before they can applied to Chile. Consequently,

Research Question 3: Do Chile and the United States display the same patterns of association among the various orientations to arguing?

\section{Method}

\subsection{Participants}

Participants were 384 students enrolled in Chilean universities. A quarter of the sample (96 respondents) came from each of four schools: University Alberto Hurtado, University de Chile, University de Santiago, and University Diego Portales. Students had a variety of undergraduate majors, with history $(N=66)$, education $(N=66)$, psychology $(N=78)$, and sociology $(N=48)$ being most common. Not quite half $(45 \%)$ of respondents were men and $51 \%$ were women, with $4 \%$ not supplying this information. The self-reported median family monthly income was between $\$ 500,000$ and $\$ 1,000,000$ Chilean pesos, equivalent to about $\$ 10,800$ to $\$ 21,600$ U.S. dollars per year, or $€ 8,100$ to $€ 16,200$ euros annually. The 
cost of living in Santiago is about three-quarters of that of many middle sized European cities (e.g., Lyon, France or Hamburg, Germany) and comparable to that in many middle sized cities in the U.S. (e.g., Tucson or Kansas City). Median educational level for the respondents' parents was Technical Certificate (roughly equivalent to a U.S. community college degree) for both the mothers and the fathers. The sample's average age was 20.6 years $(S D=4.4)$.

\subsection{Procedures}

Respondents were provided with booklets containing all the instruments. The surveys were filled out by students while they were on campus, and took about forty five minutes to complete. The materials were in Spanish. All instruments were translated from English to Spanish and then back-translated, with necessary adjustments made.

\subsection{Measures}

Respondents completed a number of instruments that were originally worded in English. Descriptive statistics, including Cronbach's alphas, are in Table 1.

The Big Three supertraits (Eysenck and Eysenck 1975; Eysenck, Eysenck and Barrett 1985) are psychoticism, extraversion, and neuroticism. This battery also produces a lie scale. Reliabilities of the psychoticism and lying scales were lower than desirable, but could not be significantly improved by omitting items.

Five argument frames (Hample, Warner and Young 2009) were assessed: Using argument to display identity, engaging in arguments for play, using arguments to assert one's dominance, seeing arguments as essentially cooperative, and anticipating that arguments are normally civil. The cooperation measure had lower reliability than would be wished.

Verbal aggressiveness (Infante and Wigley 1986) and argumentativeness (Infante and Rancer 1982) each have two subscales. The reliabilities for the verbal aggressiveness measures were somewhat low, but the argumentativeness translation performed well.

To assess editing behaviors, respondents were provided with a message production task - to get a friend to accompany you to a movie of a type the friend doesn't normally like - and asked to indicate which of the 48 provided messages they would be willing to use, and why they would not use the others. The reasons for suppression are the editorial standards (Hample and Dallinger 1987): Ineffectiveness, too negative to use, harm to self, harm to other, harm to relationship, false, and irrelevant. The present data set does not afford a measure of reliability for these choices.

Anxiety about communicating was assessed with the Personal Report of Communication Apprehension (McCroskey 1978).

The persuasion goals instrument developed by Dillard, Segrin and Harden (1989) obtains estimates of six goals: To influence the other, to protect identity, to promote 
interaction, to preserve relational resources, to protect personal resources, and to manage one's arousal. The interaction and relational resource instruments had low reliabilities.

Finally, the Singelis (1994) self-construal instrument was used, generating selfreports of the degree to which respondents had independent or interdependent orientations toward social life.

For the most part, the translated instruments had acceptable reliabilities. Several had Cronbach's alphas in the $.60 \mathrm{~s}$, which is lower than desired but still useful for data analysis. Supplementary development of additional or replacement items in Spanish may ultimately be needed to bring some instruments up to standard levels of psychometric quality.

\subsection{Comparison data}

Nearly all these instruments were also used in two investigations done in the U.S. with the original English-language instrumentation (Hample, Han and Payne 2010; Hample, Richards and Skubisz 2013). Respondents in both of those studies were undergraduates enrolled in a large public university in the mid-Atlantic region of the U.S. Further information on the data collections is available in the original published accounts. Data were cumulated from those two studies to afford comparisons for the current Chilean data, and this information also appears in Table 1.

\section{Results}

Analysis of the data is divided into several categories, according to which main issue is being addressed. We will begin by examining only the Chilean data to identify sex differences among the variables, answering our first research question. Then we will proceed to the comparative analyses that address the second and third research questions, contrasting Chilean results with those from the U.S. Those analyses will themselves be divided into two sections, one comparing the mean scores from the two nations (research question 2) and the other comparing the two nations' correlations among measures (research question 3).

\subsection{Sex differences in Chile}

Research question 1 inquired whether sex differences would be observable in Chile. Different patterns of results for men and women have been reported in the U.S. for many of the measures used here, and gender is a basic organizing principle of social perception and social interaction. Therefore we begin by comparing scores of Chilean men and women. These data are in Table 2.

Results show that men had higher scores on psychoticism, the play frame, the dominance frame, the verbal aggressiveness (antisocial) measure, and the use of relevance 
as an editorial standard. Women had higher scores on neuroticism, the cooperation frame, the civility expectation, the verbal aggressiveness (prosocial) measure, and the use of truth as an editorial criterion. Differences at the $p<.10$ (two-tailed) level included men making more use of the harm to self editorial standard, and more use of the relational and personal resource management goals. Women made more use of the harm to relationships editorial standard and were more oriented to the identity goal.

These sex differences can be summarized as indicating that Chilean men were more aggressive and self-oriented, whereas Chilean women were more concerned with the other person and the constructiveness of the interaction. These patterns of sex differences are not dissimilar from those observed in the U.S.

\subsection{Chilean and U.S. scores}

Our second research question is more general than the first one, which was aimed at discovering sex differences. Here we begin our analysis of the similarities and differences between Chile and the U.S. by comparing scores on our instruments. Table 1 contains mean scores from both Chile and the U.S. Where data from both countries was available, the final column of Table 1 indicates $t$ values for the mean differences between the two nations. Taking $t=2.00$ as the criterion for a statistically significant difference at $p<.05$, many differences appeared between the two nations. Readers should keep in mind that these mean comparisons presume that the instruments were exactly equivalent in spite of being in different languages, leaving nation as the only point of comparison. This is not entirely realistic, so the differences should be weighed with caution.

Significant differences appear throughout Table 1. Chileans had higher scores on the primary Big Three instruments than American students did. Psychoticism, neuroticism, and extraversion were all higher in Chile. Chileans, compared to Americans, were more attuned to the identity display, play, cooperation, and civility possibilities for arguing. U.S. respondents had higher scores for dominance assertion. Chileans had lower verbal aggression (antisocial) and argument avoidance scores, but higher argument approach motivations. Editorial behaviors were also somewhat different between the two nations. Chileans endorsed fewer messages overall, and made noticeably more use of the truth, relevance, and too negative to use reasons for suppression. U.S. respondents, on the other hand, were more likely to reject messages because of ineffectiveness, projected harm to other, or the possibility of harm to the relationship. Chileans self-reported higher levels of communication apprehension than U.S. respondents did. Chileans also reported a much higher level of interdependence than in the U.S., although the independence self-construal scores were not different.

Each of these significant differences has its own importance, but some general patterns seem to be present. Chileans self-reported less hurtful aggression, as evidenced by the verbal aggressiveness and dominance results. Chileans were more motivated to engage in arguing, and saw it as more cooperative and civil than U.S. respondents did. Some other evidence indicates that Chileans took less notice of relational problems (e.g., the harm to 
other and harm to relationship editorial standards). Chileans had higher interdependence orientations. A possible explanation for all this is that the practice of arguing might be less eristic and more constructive in Chile than in the U.S., but considerably more research will be needed to test that possibility.

\subsection{Chilean and U.S. patterns of association}

Our final research question asked about the associations among the measures, with the aim of discovering whether Chile and the U.S. have different variable-to-variable connections. To the degree that the present data set affords a glimpse at the dynamic relationships among the various argument-relevant motivations, predispositions, and expectations in Chile, these will be revealed by the variables' correlations. Correlation is not causality, but seeing what measures are statistically irrelevant to one another and which have clear associations would be a valuable first step in developing a theory of how interpersonal arguing works in Chile. Because so many instruments are involved in this study, the reports of associations will be divided among several tables.

Table 3 shows the correlations among the argumentativeness, verbal aggressiveness, and argument frames measures in Chile and the United States. For Chile, the approach and avoidance subscales for the argumentativeness measure are negatively correlated $(r=-.16)$ but not at a level suggesting that these are in fact mirror image scales, as they have been theorized in the U.S. The table shows that in the U.S., the same correlation was -.63. The two parallel scales for verbal aggressiveness, the prosocial and antisocial subscales, have the same negative but modest correlation in Chile, again suggesting that these scales are not behaving in Chile as they do in the U.S., where the correlation was -.51. The first order frames (identity, play, and dominance) are all positively correlated in Table 3 , indicating that the various kinds of self-orientation were associated in Chile, but the associations were all higher in the U.S. Cooperation and civility were strongly associated in Chile $(r=.37)$, indicating that the other-oriented measures were consistent with one another. This result was more marked than in the U.S., where $r=.25$. Arguing to display or feature one's own identity was positively associated with both cooperation and civility in Chile, but the play and dominance frames were negatively associated with the other-oriented frames. Similar patterns appeared in the U.S. data, but they were not so clear as in Chile.

The next set of analyses concerns the relationships among communication apprehension (measured by the PRCA) and the various editorial choices respondents could make. The correlations are in Table 4. Even a superficial examination of the table reveals that effects were generally either absent or modest. In Chile communication apprehension positively predicted concern for relationship and had negative relationships with interest in the truth or relevance of what might be said. None of these effects were significant in the U.S. sample, but the U.S. results were nonetheless somewhat consistent with the Chilean pattern. The editorial choices were not very strongly or consistently related to one another in either nation. In Chile, the person-centered codes (harm to self, other, and relationship) showed only one important association, the positive correlation between harm to other and 
harm to relationship, and parallel results appeared in the U.S. sample. Chileans seemed to be using the "too negative to use" criterion differently than Americans. In Chile, this standard was positively connected to effectiveness but that correlation was negative in the U.S. In sum, Table 4 does not seem to point to any important or substantial differences in the way Chileans and Americans edit their messages.

The next comparison concerns goal importance in Chile and in the U.S. (Table 5). For these comparisons, the U.S. data derive from Dillard, Segrin, and Harden's (1989) report. In Chile, the importance of the influence goal was most strongly associated with the interaction goal (being socially appropriate). This positive correlation also appeared in the U.S., but in that nation influence was also connected to protecting personal resources (e.g., safety) and managing arousal. In the U.S., influence was seen as negatively related to protecting relational resources (e.g., maintaining the relationship) but in Chile influence was quite consistent with relational preservation. The differences in the Chilean and American patterns for the influence goal suggest that people in the two countries have a different understanding of how one balances the desire to persuade with other possible motivations. Further comparisons within Table 5 reveal national differences in how relational and personal resources relate to one another (positively in Chile and negatively in the U.S.), the importance of the interaction goal (it is more enmeshed in the motivational system in the U.S. than in Chile), and the arousal goal, which is more consistently involved in persuasive motivations in the U.S. than in Chile.

The final points of comparison deal with the measures included in the study because of their broad capacity to explain social cognition and motivation. These are the Big Three and self-construals. Table 6 shows how those measures correlated with the others already reviewed.

Probably the main value of these results will be felt in the future as other researchers follow up on these clues by noticing correlates of the Big Three and self-construals. Nonetheless, some points of interest are already apparent. Argument-avoid and both verbal aggressiveness subscales are more strongly predicted by the Big Three and self-construals in the U.S. than in Chile, suggesting that they may be less dependent on traits in Chile (and so possibly more responsive to situational factors). Comparisons within the table also suggest that personality is more determinative of argument frames in the U.S. than in Chile, but the differences are less clear-cut. No other obvious pattern differences appear when the two nations are compared, but several of the individual correlations differ in sign and may be interesting platforms from which to conduct future research. Self-construals, perhaps the most common individual level variables used in cross-cultural research, did not have dramatic influence on arguing motivations, frames, and behaviors in either country.

Results bearing on our final research question are not easy to sum up. We found a great deal of similarity in the various correlational patterns in the two nations, but there were often some noticeable differences as well. The dynamic fields of impulse, worry, motivation, and personality traits were recognizable when the two countries were compared, but each point of marked difference might well justify a follow-up study. 


\section{Discussion}

In reflecting on our results, two patterns seem especially important: Sex differences and motivations to approach or avoid arguing and personal attacks.

The sex differences reported here give a good picture of how men and women orient to the argumentative culture of Chile. Although Chilean women are more independent today because their material conditions and opportunities have improved, some symbolic constraints are still reproduced in social argumentative practices. The pattern of men having higher scores on play and dominance frames and antisocial verbal aggressiveness and women having higher scores for cooperation and civility, is in line with more traditional gender roles: Male aggressiveness but female convergence with the group. The fact that this is similar to the U.S.'s pattern might be seen as an ancestral inheritance, if viewed from an evolutionary point of view (Hrdy 2009).

An important point of difference between Chile and the U.S. (where the instruments and theories originated) concerns the pairs of subscales for argumentativeness and verbal aggressiveness. These two variables are foundational to the study of interpersonal arguing in the U.S. (e.g., Hample 2005; Rancer and Avtgis 2014), and each assesses approach and avoidance motivations. For argumentativeness, the measure orients to engaging the other person's arguments, and for verbal aggressiveness, the instrument concerns attacks on the other person's identity. The approach and avoidance subscales are supposed to be opposites, more or less. In the U.S., the two subscales had very substantial negative correlations but in Chile the pairs had very modest negative associations (Table 3). Approach and avoidance were not diametrically opposed in Chile - they were only somewhat inconsistent impulses. In India, these pairs of scores were actually positively correlated (Hample and Anagondahalli 2015) and in China the correlations were intermediate between those found here for Chile and the United States (Xie, Hample, and Wang, in press). This patterns shows signs of being an important matter to track from one nation to another.

Overall scores for argumentativeness and verbal aggressiveness are ordinarily calculated by subtracting the avoidance score from the approach result. Where approach and avoidance are clear opposites, this makes obvious sense, and it is routinely done in the U.S. When we cannot rely on the subscale pairs being opposites, results for each subscale should be reported separately as they have been here. Should the approach/avoid correlations prove to be weak in other nations besides Chile, researchers might consider the analytic suggestion of Hamilton and Hample (2011). They proposed adding (not subtracting) the subscale scores to obtain a sort of motivational energy measure. People with high approach and avoid scores for argumentativeness are strongly pulled in both directions, and similarly for verbal aggressiveness. The strength of the pulls is operationalized by the sum of the subscale scores. These rotated scores might prove to be particularly informative in cultures where approach and avoidance impulses are more compatible with each other than in the U.S.

The fact that in Chile approach and avoidance impluses correlate negatively in a very modest way, could be related to a loss of meaning about what arguing signifies. There is an ambiguous concept of advancing a point of view among students (and probably also 
among adult people in Chile) and the effect that this could have for the person. Maybe this is part of a long history of cultural and political polarization deepened by Pinochet's dictatorship as a consequence of the habit of giving points of view without reasons, or arguments as a whole without the chance of criticizing them. Approach and avoidance are part of a discursive frame in which it is not clear what the boundaries are between, on the one hand, advancing an assertion and burden of proof, and on the other hand, what are private and public deliberative responsibilities.

It is salient that Chilean scores were higher than for U.S. respondents on four of the five argumentative frames (identification, play, cooperation, and civility; Americans had a higher mean for dominance). This difference can be explained by the fact that Chilean communicative culture has a clear tendency to courtesy (Puga 1997) where any hostility is avoided and euphemisms are common. The higher U.S. scores for the dominance frame might be the result of more direct and individualistic communicative behaviour.

A special degree of prosociality in Chile is also suggested by the results for the approach and avoid argumentative motivations, which contrast to the anti-social verbal aggressiveness means, which were higher in the U.S. respondents. The results for editing choices also coincide with this line of analysis: Chileans were more likely to reject a possible argument as being false, irrelevant, or too negative. This means that any message that can be seen as damaging social relationships would be especially avoided in Chile. The cost of this general pattern of behavior might be an incapacity to resolve differences of opinion in easier and shorter ways, particularly given a tendency to euphemism.

The correlations between argumentative frames and argumentative motivations show that in Chile there were clear associations between pro-social argument frames (play, identification and civility) and argument approach motivation. In fact, cooperation had a very high correlation with the pro-social verbal aggressiveness subscale, and conversely dominance correlated substantially with antisocial verbal aggressiveness among Chileans respondents. Compared to Americans, among whom there was a high correlation between dominance frame and antisocial verbal aggressiveness (and a negative correlation between dominance and pro-social verbal aggressiveness) and a lower positive correlation between civility frame and pro-social aggressiveness, Chileans seemed to see argumentation as a 'point of reunion' rather than a space of disagreement to show certain types of power or status. In this respect, Chilean argumentative culture can be seen as more ambiguous and polite in practice, instead of a more direct, agonistic and competitive disposition as in the U.S.

At first sight, it could be striking that no other dramatic differences between Chile and the U.S. were found. The post-Pinochet young students are, in some ways, similar to young American college students, perhaps due to globalized media. The differences already pointed out are still interesting in terms of a more subtle appreciation of cultural background. The comparisons reported here, whether they displayed similarity or difference, are encouraging for the prospect of developing a uniquely Chilean theory of argumentative practice, and using that work to re-inform U.S. theory. 
Table 1: Descriptive Statistics

\begin{tabular}{|c|c|c|c|c|c|c|c|c|c|}
\hline & & & Chile & & & & U.S. & & \\
\hline Measure & alpha & $\overline{\text { items }}$ & $\mathrm{N}$ & Mean & $\mathrm{SD}$ & $\mathrm{N}$ & Mean & SD & $\bar{t}$ \\
\hline \multicolumn{10}{|l|}{ Big Three } \\
\hline Psychoticism & .57 & 12 & 377 & .39 & .19 & 228 & .24 & .10 & 12.69 \\
\hline Extraversion & .73 & 11 & 376 & .64 & .24 & 228 & .57 & .14 & 4.53 \\
\hline Neuroticism & .77 & 12 & 377 & .53 & .25 & 228 & .37 & .18 & 9.12 \\
\hline Lying & .60 & 11 & 375 & .35 & .20 & 228 & .37 & .14 & 1.44 \\
\hline \multicolumn{10}{|l|}{ Argument Frames } \\
\hline Identification & .74 & 8 & 383 & 3.91 & .60 & 419 & 3.51 & .55 & 9.81 \\
\hline Play & .73 & 4 & 383 & 2.99 & .92 & 419 & 2.60 & .87 & 6.15 \\
\hline Dominance & .81 & 6 & 384 & 2.32 & .85 & 419 & 2.63 & .70 & 5.61 \\
\hline Cooperation & .66 & 5 & 383 & 4.05 & .64 & 419 & 3.64 & .49 & 10.12 \\
\hline Civility & .70 & 10 & 364 & 3.77 & .50 & 419 & 3.39 & .48 & 10.81 \\
\hline \multicolumn{10}{|c|}{ Argument Approach/Avoid } \\
\hline Verb Agg - antisoc & .69 & 10 & 382 & 2.29 & .58 & 420 & 2.45 & .63 & 3.74 \\
\hline Verb Agg - prosoc & .62 & 9 & 383 & 3.41 & .60 & 420 & 3.39 & .52 & 0.50 \\
\hline Arg Avoid & .75 & 10 & 384 & 2.22 & .61 & 420 & 3.11 & .64 & 20.18 \\
\hline Arg Approach & .82 & 10 & 384 & 3.47 & .68 & 420 & 3.05 & .67 & 8.81 \\
\hline \multicolumn{10}{|c|}{ Editing Choices (Max 48) } \\
\hline Endorse & - & -- & 384 & 9.39 & 6.26 & 229 & 12.54 & 7.44 & 5.37 \\
\hline Ineffective & -- & -- & 384 & 7.06 & 7.08 & 229 & 8.30 & 7.94 & 1.95 \\
\hline Too Negative & -- & -- & 384 & 6.84 & 6.99 & 229 & 5.50 & 6.67 & 2.36 \\
\hline Harm Self & -- & -- & 384 & 1.41 & 2.46 & 229 & 1.35 & 3.14 & 0.25 \\
\hline Harm Other & -- & -- & 384 & 2.45 & 3.67 & 229 & 3.80 & 5.76 & 3.18 \\
\hline Harm Relation & -- & -- & 384 & 2.71 & 3.44 & 229 & 3.15 & 4.69 & 1.24 \\
\hline False & -- & -- & 384 & 7.52 & 8.36 & 229 & 5.09 & 7.52 & 3.71 \\
\hline Irrelevant & -- & -- & 384 & 6.59 & 7.51 & 229 & 5.08 & 5.86 & 2.77 \\
\hline Residual & -- & -- & 384 & 3.10 & 5.96 & 229 & 2.15 & 4.56 & 2.22 \\
\hline Comm Appreh & 93 & 24 & 379 & 2.85 & .23 & 192 & 2.42 & .57 & 10.05 \\
\hline \multicolumn{10}{|l|}{ Interaction Goals } \\
\hline Influence & .79 & 2 & 365 & 2.89 & .93 & & & & \\
\hline Identity & .85 & 4 & 367 & 3.71 & .79 & & & & \\
\hline Interaction & .63 & 4 & 366 & 3.27 & .69 & & & & \\
\hline Relat Resource & .60 & 3 & 366 & 2.66 & .56 & & & & \\
\hline Personal Resource & .73 & 3 & 366 & 2.56 & .78 & & & & \\
\hline Arousal & .74 & 2 & 366 & 2.77 & .90 & & & & \\
\hline \multicolumn{10}{|c|}{ Self Construals (7 Points) } \\
\hline Singelis Indep & .74 & 12 & 364 & 4.64 & .88 & 195 & 4.63 & .57 & 0.16 \\
\hline Singelis Interdep & .76 & 12 & 363 & 5.33 & .90 & 193 & 4.47 & .59 & 13.54 \\
\hline
\end{tabular}


Notes. The Big Three variables are on a 0-1 scale, on which 0 means "no" and 1 means "yes." The Singelis variables are on a 1-7 scale. The editing items are counts, each with a maximum value of 48. Other variables were on a 1-5 scale. In every case, a higher number means more of the named construct.

The U.S. data were taken from the data sets for Hample, Han, and Payne (2010) and Hample, Richards, and Skubisz (2013). Blanks in the U.S. columns mean no data was available.

Where necessary, the U.S. data were converted to the Chilean scale using this procedure: subtract 1 if necessary to make the scale minimum 0 ; divide the result by the range of the original scale, so that the scale now goes from 0 to 1 ; multiply by the range of the new scale; add 1 if necessary to make the new scale's minimum 1 . Standard deviations were converted by multiplying the original S.D. by the ratio of the two scale's ranges.

Table 2: Sex Differences in Chile (Means)

\begin{tabular}{|c|c|c|c|}
\hline & & Chile & \\
\hline & Men & Women $t$ & \\
\hline Psychoticism & .43 & .36 & $3.70 * * *$ \\
\hline Extraversion & .62 & .65 & 1.18 \\
\hline Neuroticism & .49 & .55 & $2.37 *$ \\
\hline Lying & .34 & .36 & 0.86 \\
\hline Identity & 3.89 & 3.94 & 0.88 \\
\hline Play & 3.19 & 2.78 & $4.44 * * *$ \\
\hline Dominance & 2.49 & 2.18 & $3.63 * * *$ \\
\hline Cooperation & 3.96 & 4.14 & $2.66 * *$ \\
\hline Civility & 3.70 & 3.81 & $2.14^{*}$ \\
\hline VA-antisocial & 2.39 & 2.22 & $2.73 * *$ \\
\hline VA-prosocial & 3.33 & 3.49 & $2.51 *$ \\
\hline Arg-avoid & 2.27 & 2.20 & 1.12 \\
\hline Arg-approach & 3.50 & 3.42 & 1.11 \\
\hline Endorsement & 9.28 & 9.39 & 0.16 \\
\hline Ineffective & 7.48 & 6.93 & 0.73 \\
\hline Too Negative & 6.29 & 7.47 & 1.60 \\
\hline Harm Self & 1.63 & 1.20 & 1.69\# \\
\hline Harm Other & 2.48 & 2.42 & 0.16 \\
\hline Harm Relation & 2.41 & 3.00 & $1.66 \#$ \\
\hline False & 6.41 & 8.27 & $2.16^{*}$ \\
\hline Irrelevant & 7.84 & 5.46 & $2.95 * *$ \\
\hline Residual & 3.42 & 2.69 & 1.22 \\
\hline Comm Appreh & 2.85 & 2.86 & 0.63 \\
\hline Influence & 2.89 & 2.91 & 0.21 \\
\hline
\end{tabular}




$\begin{array}{llll}\text { Identity } & 3.62 & 3.78 & 1.85 \# \\ \text { Interaction } & 3.25 & 3.31 & 0.75 \\ \text { Relational Resource } & 2.71 & 2.60 & 1.82 \# \\ \text { Personal Resource } & 2.64 & 2.50 & 1.69 \# \\ \text { Arousal } & 2.75 & 2.78 & 0.41 \\ & & & \\ \text { Independence } & 4.59 & 4.68 & 0.94 \\ \text { Interdependence } & 5.29 & 5.38 & 0.95\end{array}$

Note. Significance tests are from independent sample t-tests with about 350 degrees of freedom. All tests were two-tailed.

$\# p<.10 \quad * p<.05 \quad * * p<.01 \quad * * * p<.001$

Table 3: Correlations Among Approach/Avoid Motivations and Argument Frames in Chile and the United States

\begin{tabular}{lcccccccc}
\hline & 1 & 2 & 3 & 4 & 5 & 6 & 7 & 8 \\
\hline 1 Arg-Approach & & & & Chile & & & & \\
2 Arg-Avoid & -.16 & & & & & & & \\
3 VA-Prosocial & .02 & -.14 & & & & & & \\
4 VA-Antisocial & .26 & .14 & -.16 & & & & & \\
5 Identification & .33 & -.08 & .13 & .12 & & & & \\
6 Play & .44 & -.13 & -.14 & .27 & .18 & & & \\
7 Dominance & .27 & .27 & -.24 & .36 & .15 & .39 & & \\
8 Cooperation & .08 & -.18 & .38 & -.17 & .30 & -.09 & -.31 & \\
9 Civility & .24 & -.44 & .25 & -.12 & .25 & -.02 & -.29 & .37 \\
\hline
\end{tabular}

1 Arg-Approach

2 Arg-Avoid

United States

3 VA-Prosocial $\quad .05 \quad .12$

4 VA-Antisocial $\quad .08 \quad .08 \quad-.51$

$\begin{array}{lllll}5 \text { Identification } & .03 & .08 & -.13 & .29\end{array}$

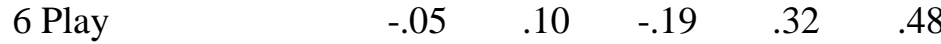

$\begin{array}{lllllll}7 \text { Dominance } & .12 & .01 & -.37 & .51 & .27 & .31\end{array}$

$\begin{array}{llllllll}8 \text { Cooperation } & -.06 & .13 & .44 & -.31 & .12 & -.15 & -.27\end{array}$

$\begin{array}{lllllllll}9 \text { Civility } & .02 & -.05 & .26 & -.19 & .12 & .17 & -.26 & .25\end{array}$

Note. For Chile, $N$ is between 364 and 384 for all the correlations. Correlations with |.10| or more are statistically significant at $p<.05$, two-tailed. For the U.S., $N$ is about 420 for all the correlations. Correlations with $|.10|$ or more are statistically significant at $p<.05$, two-tailed. 
Table 4: Correlations Among Communication Apprehension and Editing Choices in Chile and the United States

\begin{tabular}{|c|c|c|c|c|c|c|c|c|c|}
\hline & 1 & 2 & 3 & 4 & 5 & 6 & 7 & 8 & 9 \\
\hline \multicolumn{10}{|c|}{ Chile } \\
\hline 1 PRCA & & & & & & & & & \\
\hline 2 Endorse & .05 & & & & & & & & \\
\hline 3 Ineffective & .04 & -.01 & & & & & & & \\
\hline 4 Too Negative .05 & .04 & .12 & & & & & & & \\
\hline 5 Harm Self & .01 & -.12 & -.06 & -.08 & & & & & \\
\hline 6 Harm Other & .05 & -.10 & -.12 & -.09 & -.03 & & & & \\
\hline 7 Harm Relation & .16 & -.05 & .02 & .08 & .06 & .24 & & & \\
\hline 8 False & -.10 & -.03 & .05 & .02 & .00 & -.15 & -.17 & & \\
\hline 9 Irrelevant & -.10 & .06 & .00 & 0.04 & -.02 & -.16 & -.08 & -.18 & \\
\hline 10 Residual & -.02 & .11 & -.07 & .05 & .01 & -.09 & -.06 & -.16 & -.09 \\
\hline
\end{tabular}

1 PRCA

2 Endorse $\quad .02$

3 Ineffective $\quad .00 \quad .04$

4 Too Negative $.01 \quad-.08 \quad-.09$

$\begin{array}{lllll}5 \text { Harm Self } & .11 & -.05 & .04 & -.11\end{array}$

$\begin{array}{llllll}6 \text { Harm Other } & .09 & .01 & .14 & .00 & -.01\end{array}$

$\begin{array}{lllllll}7 \text { Harm Relation } & .09 & -.03 & .03 & -.05 & -.07 & .21\end{array}$

$\begin{array}{llllllll}8 \text { False } & -.03 & -.03 & -.09 & .10 & -.16 & -.05 & .02\end{array}$

$\begin{array}{lllllllll}9 \text { Irrelevant } & -.02 & -.09 & .03 & .14 & -.07 & .01 & .15 & .06\end{array}$

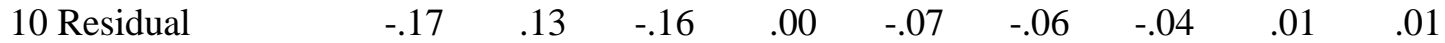

Note. For Chile, $N$ is between 355 and 385 for all the correlations. Correlations with |.10| or more are statistically significant at $p<.05$, two-tailed. For the U.S., $N$ is about 190 for all the correlations. Correlations with $|.14|$ or more are statistically significant at $p<.05$, two-tailed.

Table 5: Correlations Among Communication Apprehension and Interaction Goals in Chile and the United States

\begin{tabular}{lccccc}
\hline & 1 & 2 & 3 & 4 & 5 \\
\hline 1 Influence & & & Chile & & \\
2 Identity & .04 & & & & \\
3 Interaction & .25 & .29 & & & \\
4 Relational Resource & .12 & -.18 & .07 & & \\
5 Personal Resource & -.01 & -.05 & .05 & .27 & \\
6 Arousal & .10 & .08 & .26 & .08 & .41 \\
& & & & & \\
\hline
\end{tabular}


1 Influence

2 Identity

3 Interaction

United States

4 Relational Resource

5 Personal Resource

.40

6 Arousal

$\begin{array}{lll}-.29 & .03 & .12\end{array}$

$\begin{array}{llll}.20 & .11 & .29 & -.17\end{array}$

$\begin{array}{lllll}.27 & .24 & .47 & .00 & .37\end{array}$

Note. For Chile, $N$ is between 355 and 385 for all the correlations. Correlations with |.10| or more are statistically significant at $p<.05$, two-tailed. For the U.S., the table reproduces the results from sample 1 in Dillard, Segrin, \& Harden (1989), Table 4. $N=293$, and correlations with |.12| or more are statistically significant.

Table 6: Correlations Between the Big Three, Self-Construals, and Argument-Relevant Measures in Chile and the United States

\begin{tabular}{|c|c|c|c|c|c|c|}
\hline & 1 & 2 & 3 & 4 & 5 & 6 \\
\hline \multicolumn{7}{|c|}{ Chile } \\
\hline Arg-Approach & .07 & .22 & .08 & -.06 & -.04 & .29 \\
\hline Arg-Avoid & -.06 & -.15 & -.15 & -.01 & .14 & -.19 \\
\hline VA-Prosocial & -.12 & -.02 & -.02 & .13 & .08 & .24 \\
\hline VA-Antisocial & .19 & .06 & .08 & -.19 & -.04 & .06 \\
\hline Identification & -.13 & .06 & .11 & .03 & .05 & .31 \\
\hline Play & .26 & -.01 & -.02 & -.20 & -.10 & .04 \\
\hline Dominance & .18 & -.09 & .09 & -.10 & -.09 & -.03 \\
\hline Cooperation & -.19 & -.03 & .04 & .12 & .16 & .28 \\
\hline Civility & -.05 & .07 & -.02 & .09 & -.01 & .22 \\
\hline PRCA & -.12 & -.06 & .07 & -.02 & .12 & -.11 \\
\hline Endorse & .05 & .10 & .13 & -.16 & -.03 & .11 \\
\hline Ineffective & .03 & .00 & -.00 & .01 & .01 & -.05 \\
\hline Too Negative & -.20 & .06 & -.00 & .09 & .04 & .11 \\
\hline Harm Self & .09 & -.10 & .03 & .03 & -.07 & -.10 \\
\hline Harm Other & -.01 & -.13 & .06 & .00 & -.03 & -.10 \\
\hline Harm Relationship & .00 & -.13 & .05 & .10 & .06 & -.05 \\
\hline False & .02 & .04 & -.01 & -.05 & .00 & .05 \\
\hline Irrelevant & .12 & -.05 & -.11 & .04 & -.02 & -.01 \\
\hline Residual & .01 & .02 & -.06 & -.04 & .01 & -.09 \\
\hline \multicolumn{7}{|c|}{ United States } \\
\hline Arg-Approach & .04 & .12 & .05 & -.09 & -.14 & .38 \\
\hline Arg-Avoid & -.24 & -.12 & .28 & .05 & .22 & -.14 \\
\hline VA-Prosocial & -.25 & .04 & -.28 & .33 & .07 & .29 \\
\hline VA-Antisocial & .22 & -.00 & .36 & -.34 & -.04 & -.04 \\
\hline Identification & -.02 & .01 & .23 & -.18 & .10 & .02 \\
\hline Play & .26 & -.04 & .12 & -.26 & .02 & -.11 \\
\hline Dominance & .10 & -.04 & .29 & -.25 & -.07 & .01 \\
\hline
\end{tabular}




$\begin{array}{lcccccc}\text { Cooperation } & -.24 & .12 & -.08 & .17 & .03 & .25 \\ \text { Civility } & -.01 & .07 & -.24 & .13 & -.02 & -.05 \\ \text { PRCA } & -- & -- & -- & -- & -- & -- \\ \text { Endorse } & .10 & .09 & .02 & -.09 & .02 & .05 \\ \text { Ineffective } & -.05 & -.14 & .07 & -.09 & .04 & .04 \\ \text { Too Negative } & -.04 & .04 & .00 & .06 & -.08 & -.09 \\ \text { Harm Self } & .14 & .01 & -.09 & .14 & -.05 & .04 \\ \text { Harm Other } & .09 & -.12 & -.01 & .01 & .01 & .14 \\ \text { Harm Relationship } & -.12 & -.05 & .05 & .09 & -.03 & .03 \\ \text { False } & .09 & -.07 & .05 & .02 & -.03 & -.09 \\ \text { Irrelevant } & -.13 & .04 & -.04 & -.00 & -.09 & .03 \\ \text { Residual } & .03 & .20 & -.04 & -.08 & .13 & -.16\end{array}$

Note. 1 = Psychoticism, 2 = Neuroticism, 3 = Extraversion, 4 = Lying, 5 = Independent SelfConstrual, and $6=$ Interdependent Self-Construal. For Chile, correlations with |.10| or more are statistically significant at $p<.05$, two tailed. For the U.S., correlations with $|.14|$ or more are statistically significant at $p<.05$, two tailed.

\section{References}

Avtgis, Theodore A., Andrew S. Rancer, Penka .A. Kanjeva, and Rebecca M. Chory (2008) Argumentative and aggressive communication in Bulgaria: Testing for conceptual and methodological equivalence. Journal of Intercultural Communication Research 37: 17-24.

Baño, Rodrigo, Carlos Ruiz, and María Eugenia Ruiz-Tagle (2008) Enzo Faletto: Obras Completas. Tomo I. Santiago: Random House Mondadori.

Cademartori, Yanina, and Dolores Parra (2004) Reforma educativa y teoría de la argumentación. Revista Signos 33.48: 69-85.

Cionea, Ioana A., Dale Hample, and Fabio Paglieri (2011) A test of the argument engagement model in Romania. In F. Zenker (ed.), Argument cultures: Proceedings of the $8^{\text {th }}$ international conference of the Ontario Society for the Study of Argumentation (OSSA), May 18-21, 2011. Windsor, ON: Ontario Society for the Study of Argumentation.

Cordero, Marcela. (2004) El componente 'tesis' en los textos argumentativos escolares. Revista Signos 33.48: 87-96.

Crespo, Nina (2005) La importancia de la argumentación matemática en el aula. Premisa. Revista de la Sociedad Argentina de Educación Matemática 7.23: 23-29.

Croucher, Stephen (2013) The difference in verbal aggressiveness between the United States and Thailand. Communication Research Reports 30.3: 264-269. 
Croucher, Stephen M., Deepa Oommen, Manda V. Hicks, Kyle J. Holody, Samura Yoon Anarbaeva, Spencer Antony T. Kisung, Chrishawn Marsh, and Abdulrahman I. Aljahli (2010) The effects of self-construal and religiousness on argumentativeness: A cross-cultural analysis. Communication Studies 61: 135-155.

Croucher, Stephen M., Rand Otten, Methan Ball, Tamara Grimes, Brett Ainsworth, Kieran Begley, and Laci Corzo (2013) Argumentativeness and political participation: A cross-cultural analysis in the United States and Turkey. Communication Studies 64.1: 18-32.

Dillard, James (1990) A goal-driven model of interpersonal influence. In J.P. Dillard (ed.), Seeking compliance: The production of interpersonal influence messages. Scottsdale, AZ: Gorsuch Scarisbrick, pp. 41-56.

Dillard, James Price, Chris Segrin, and Janie M. Harden (1989) Primary and secondary goals in the production of interpersonal influence messages. Communication Monographs 56: 19-38.

Eysenck, H.J., and S.B.G. Eysenck (1975) Manual of the Eysenck personality questionnaire. London: Hodder and Stoughton.

Eysenck, S.B.G., H.J. Eysenck, and Paul Barrett (1985) A revised version of the psychoticism scale. Personality and Individual Difference 6: 21-29.

González, Cristian (2009) La interacción verbal argumentativa en la sala de clases: La participación de los alumnos y el rol de profesor. RLA 47.1: 125-144.

Goodnight, Thomas (1982) The personal, technical, and public spheres of argument: A speculative inquiry into the art of public deliberation. Journal of the American Forensic Association 18: 214-227.

Hamilton, Mark A., and Dale Hample (2011) Testing hierarchical models of argumentativeness and verbal aggressiveness. Communication Methods and Measures 5: 250-273.

Hample, Dale (2003) Arguing skill. In J.O. Greene, and B.R. Burleson (eds.), Handbook of communication and social interaction skills. Mahwah, NJ: Erlbaum, pp. 439-478.

Hample, Dale (2005) Arguing: Exchanging reasons face to face. Mahwah, NJ: Lawrence Erlbaum Associates.

Hample, Dale, and Deepa Anagondahalli (2015) Understandings of arguing in India and the United States: Argument frames, personalization of conflict, argumentativeness, and verbal aggressiveness. Journal of Intercultural Communication Research 44: 1-26.

doi:10.1080/17475759.2014.1000939

Hample, Dale, and Judith M. Dallinger (1987) Cognitive editing of argument strategies. Human Communication Research 14: 123-144.

Hample, Dale, and Judith M. Dallinger (1992) The use of multiple goals in cognitive editing of arguments. Argumentation and Advocacy 28: 109-122.

Hample, Dale, Adam S. Richards, and Christina Skubisz (2013) Blurting. Communication Monographs 80: 503-532.

Hample, Dale, Benjamin Warner, and Dorian Young (2009) Framing and editing interpersonal arguments. Argumentation 23: 21-37. 
Herrera, Florencia, and Berta Teitelboim (2011) La mirada de los chilenos a la familia. In Sexta encuesta nacional UDP. Chile 2010: Percepciones y actitudes sociales. Santiago: ICSO-UDP, pp. 121-135.

Hrdy, Sarah (2009) Mothers and Others. The Evolutionary origins of Mutual Understanding. Cambridge, Mass.: Harvard University Press.

Infante, Dominic A., and Andrew S. Rancer (1982) A conceptualization and measure of argumentativeness. Journal of Personality Assessment 46: 72-80.

Infante, Dominic A., and Charles J. Wigley (1986) Verbal aggressiveness: An interpersonal model and measure. Communication Monographs 53: 61-69.

Jélvez, Lorena (2008) Esquemas argumentativos en textos escritos: un estudio descriptivo en alumnos de tercero medio de dos establecimientos de Valparaíso. Cyber Humanitatis 45: 1-21.

Johnson, Amy (2002) Beliefs about arguing: A comparison of public issue and personal issue arguments. Communication Reports 15: 99-112.

Larraín, Antonia, and Paulina Freire (2012) El uso de discurso argumentativo en la enseñanza de ciencias: Un estudio exploratorio. Estudios Pedagógicos 38.2: 133-155.

Marinkovich, Juana (2007a) Las estrategias cognitivo-retóricas y la dimensión dialéctica de la argumentación oral en una clase de lengua castellana y comunicación. Revista Signos 40.63: 127-146.

Marinkovich, Juana (2007b) La interacción argumentativa en el aula: Fases de la argumentación y estrategias de cortesía verbal. In C. Santibáñez, and B. Riffo (eds.), Estudios en Argumentación y Retórica. Teorías contemporáneas y aplicaciones. Concepción: Universidad de Concepción Press, pp. 227-252.

Marinkovich, Juana, and Pilar Morán (1995) La calidad del texto argumentativo en estudiantes de 4 medio: Algunos rasgos significativos. Estudios Filológicos 30: 48-56.

McCroskey, James (1978) Validity of the PRCA as an index of oral communication apprehension. Communication Monographs 45: 192-203.

Meza, Paulina (2009) Las interacciones argumentativas orales en la sala de clases: Un análisis dialéctico y retórico. Unpublished Master Thesis, Pontificia Universidad Católica de Valparaíso, Chile.

O’Ryan, Raúl, Carlos de Miguel, and Camilo Lagos (2007) Evaluación de Estrategias de Desarrollo para Alcanzar los Objetivos del Milenio en América Latina. El Caso de Chile. Santiago: PNUD.

Moulian, Tomás (2009) Contradicciones del desarrollo político chileno: 1920-1990. Santiago: Ediciones LOM.

Parodi, Giovanni (2000) La evaluación de la producción de textos escritos argumentativos: Una alternancia cognitivo/discursiva. Revista Signos 33.47 : 151-16.

Poblete, Claudia (2003) Relación entre competencia textual argumentativa y metacognición. Unpublished doctoral dissertation Pontificia Universidad Católica de Valparaíso.

Puga, Juana (1997) La Atenuación en el Castellano de Chile. Un enfoque pragmalingüístico. Valencia: Universitat de Valéncia. 
Rancer, Andrew S., and Theodore A. Avtgis (2014) Argumentative and aggressive communication. 2d. Ed. New York: Peter Lang.

Salazar, Juan (2008) Estrategias de cortesía verbal en interacciones argumentativas ocurridas en contexto escolar. Alpha 27: 77-92.

Santibáñez, Cristián (2006) Retórica y argumentación en la política de sentencias populares. Praxis: Revista de Psicología y Ciencias Humanas 9: 183-196.

Santibáñez, Cristián (2010) Metaphors and argumentation: The Case of Chilean Parliamentarian Media Participation. Journal of Pragmatics 42.4: 973-989.

Singelis, Theodore (1994) The measurement of independent and interdependent self-construals. Personality and Social Psychological Bulletin 20: 580-591.

Torche, Florencia, and Guillermo Wormald (2004) Estratificación y movilidad social en Chile: Entre la adscripción y el logro. Serie Políticas públicas 98: 1-85.

Vicuña, Ana, and Juana Marinkovich (2008) Un análisis de la discusión acerca de temas controversiales en Enseñanza Media desde la pragma-dialéctica. Revista Signos 41.68: 439-457.

Vitale, Luis (2001) Balance de dos décadas de Neoliberalismo. Santiago: Universidad de Chile.

Wittig, Fernando (2005) Perspectivas argumentales en disputa en torno a la distribución de la 'píldora del días después'. Alpha 21: 159-175.

Xie, Yun, Dale Hample, and Xiaoli Wang (in press) A cross-cultural analysis of argument predispositions in China: Argumentativeness, verbal aggressiveness, argument frames, and personalization of conflict.

Argumentation. doi: $10.1007 / \mathrm{s} 10503-015-9352-8$

CRISTÍAN SANTIBÁÑEZ holds a Ph.D. in linguistics (2005, University of Houston, USA), and works at the Centre for the Study of Argumentation and Reasoning (CEAR) of the Faculty of Psychology at Diego Portales University, Santiago, Chile. During 2009-2010 he developed a postdoc research about the problem of relevance from the point of view of cognition and argumentation theory. Currently he is working on the interface between linguistics and psychology of reasoning to analyze the components of argumentative competence. Some of his publications can be found in Journal of Pragmatics, Informal Logic, Signos, RLA, among other journals. He is director of the journal Cogency. Journal of Reasoning and Argumentation (www.cogency.udp.cl) of CEAR.

Address: Centro de Estudios de la Argumentación y el Razonamiento, Facultad de Psicología, Universidad Diego Portales, Santiago, Chile. E-mail: cristian.santibanez@udp.cl 
DALE HAMPLE received his Ph.D. in communication from the University of Illinois in 1975. His dissertation applied probabilistic modeling to intrapersonal argumentation. This established several themes that have persisted in this work for almost four decades: A commitment to studying argumentation with social scientific methods, an interest in the cognitive foundations of arguing, and an understanding of arguing as a basic element of social relationships and interactions. Among his lines of research are these topics: A cognitive model of arguing, taking conflict personally, cognitive editing of arguments, and argument frames. He worked at Western Illinois University for 30 years, and is now at the University of Maryland. He spent several weeks at the University Diego Portales and the University de la Serena in the Fall of 2013. Address: Department of Communication, University of Maryland, United States. E-mail: dhample @umd.edu 